\title{
Incidence and characteristics of spinal injuries in the victims of intimate partner violence (IPV)
}

\author{
Gaurav V. Watane ${ }^{1} \cdot$ Babina Gosangi $^{2} \cdot$ Richard Thomas $^{3} \cdot$ Rahul Gujrathi $^{1} \cdot$ Hyesun Park $^{1} \cdot$ Mitchel B. Harris $^{4} \cdot$ \\ Bharti Khurana ${ }^{1}$ (1D)
}

Received: 25 August 2020 / Accepted: 17 September 2020 / Published online: 1 October 2020

(C) American Society of Emergency Radiology 2020

\begin{abstract}
Purpose To describe the incidence and patterns of the spinal injuries in the victims of physical IPV. Materials and methods With institutional review board (IRB) approval, we retrospectively reviewed patients referred to our institution's domestic violence intervention and prevention program with a diagnosis directly related to physical abuse between January 2013 and June 2018. Electronic health records and radiology reports were reviewed for all patients.

Results A total of 21/688 (3\%) IPV patients with 41 vertebral injuries were identified. The study population comprised of $19 / 21$ $(90 \%)$ females. Median age of the included patients was 43 years with a range of 21-72 years. All vertebral injuries were AO type A spinal injuries. Upper lumbar spine (L1 and L2) was the most common level of injury followed by upper to mid-thoracic spine. The reported mechanism of the injury was IPV in $8 / 21$ (38.0\%), fall in 8/21(38.0\%), and incidental in 5/21 (24.0\%). Ten out of 21 $(48 \%)$ patients had concomitant injuries, most commonly to the craniofacial region $5 / 21(23 \%)$. Psychiatry history was positive in $17 / 21(81 \%)$, and substance abuse was positive in $15 / 21(71 \%)$ of the patients.

Conclusion Incidence of spinal injuries is relatively low in IPV with morphologic AO type A injury being the most common type of injury and the upper lumbar spine being the most common level of injury.
\end{abstract}

Keywords Intimate partner violence $\cdot$ IPV $\cdot$ Spine $\cdot$ Spinal injury $\cdot$ Vertebral fracture $\cdot$ Compression fracture $\cdot$ Spinal cord injury

\section{Introduction}

Nearly 1 in 4 women and 1 in 7 men have experienced severe form of physical violence, including being struck with a hard object, being kicked or beaten, or being burned according to the National Intimate Partner and Sexual Violence Survey in the USA in 2010 [1]. Intimate partner violence (IPV) is a preventable health problem and describes a threatened or

Bharti Khurana

bkhurana@bwh.harvard.edu

1 Division of Emergency Radiology, Department of Radiology, Brigham \& Women's Hospital, 75 Francis St, Boston, MA 02115, USA

2 Department of Radiology, Yale New Haven Health, New Haven, CT 06510, USA

3 Lahey Hospital and Medical Center, 41 Mall road, Burlington, MA 01805, USA

4 Department of Orthopedic Surgery, Massachusetts General Hospital, Boston, MA, USA actual physical, sexual, or psychological harm perpetrated by a current or former spouse or a partner. It has significant implications on the physical, mental, and social well-being of the individual victims and results in a high socioeconomic burden on the general population. While the estimation of the effect of IPV on the mental health is immense and probably immeasurable objectively, the estimated population economic burden reaches up to 3.6 trillion US dollars over lifetimes of the victims with nearly $60 \%$ of this resulting from medical costs [2].

Healthcare providers can play a critical role in detecting IPV and preventing its perpetuation. Although screening questionnaires have helped, the proportion of cases identified on the basis of self-reporting represents only the tip of the iceberg. The role of radiology in detecting IPV has only been recently explored $[3,4]$. Recognizing and documenting common and uncommon injury patterns linked to IPV on radiological studies can help identify victims early and thereby potentially saving lives.

Although common sites of IPV injuries include craniofacial structures, abdominal, genital areas, and extremities, a perpetrator could potentially avoid these known exposed sites 
and target the spine and back area, especially in the early stages of abuse or very late in the cycle of abuse [4]. The literature about the spinal injuries from IPV is anecdotal and limited to a few case reports [5] or as a small part of descriptive studies [6] assessing injuries in the IPV victims without attention to spine-specific findings. Therefore, the purpose of our study is to improve early identification of IPV by recognizing the incidence, patterns, and distribution of spinal injuries seen in known victims.

\section{Materials and methods}

\section{Patient selection}

IRB approval was obtained, and informed consent was waived for our Human Insurance Portability and Accountability act (HIPAA) compliant retrospective observational cohort study. We searched the electronic medical records of our large tertiary care academic hospital for patients referred to the domestic violence intervention and prevention program with a history of IPV between January 2013 and June 2018, resulting in a total of 1248 unique patients. Using our institutional research patient data registry, we excluded 580 patients with no radiological studies. The remaining 688 patients had imaging studies and were analyzed for injuries. Four emergency radiology fellows reviewed all the radiology reports of the remaining 688 patients to identify those with spinal injuries. Six hundred sixty-seven patients with negative spine CT $(n=667)$ were excluded, and a total of $21 \mathrm{IPV}$ patients with spinal injuries constituted the final cohort.

\section{Record review}

Electronic health record (EHR) was reviewed for age, sex, race, and medical information, including a history of substance abuse, presence of mental illness, type of insurance (private or public), and presence of other concomitant injuries for all 21 patients. The reported mechanism of injury and documentation of screening for IPV at the time of the injury was also recorded.

Analysis of the spinal injuries The injuries were divided into 3 groups based on the reported mechanism of the injury and estimated age of injury on imaging studies (Table 1). We used AO spine classification to describe the type of injury with type A (compression), type B (tension band disruption), and type C (displacement/translation) injuries [7, 8]. For the location of the fracture, we reported the level of fracture and divided fractures into vertebral "body" and vertebral "process" fractures. Vertebral process fractures included fractures of the transverse process, lamina, pedicle, and spinous process.

Data entry and statistical analysis Data entry and analysis was performed in Research Electronic Data Capture (REDCap) [9].
Table 1 Demographics and pattern of vertebral injuries related to physical IPV

\begin{tabular}{|c|c|c|c|c|}
\hline Parameter & $\begin{array}{l}\text { IPV with } \\
\text { acute } \\
\text { injuries } \\
(n=3)\end{array}$ & $\begin{array}{l}\text { Fall with } \\
\text { acute } \\
\text { injuries } \\
(n=6)\end{array}$ & $\begin{array}{l}\text { Chronic or } \\
\text { age } \\
\text { indeterminate } \\
\text { injuries } \\
(n=12)\end{array}$ & $\begin{array}{l}\text { Total } \\
(n=21)\end{array}$ \\
\hline $\begin{array}{l}\text { No. of } \\
\text { vertebrae } \\
\text { injured }\end{array}$ & 7 & 11 & 20 & 38 \\
\hline $\begin{array}{l}\text { No. of } \\
\text { fractures }\end{array}$ & 8 & 13 & 20 & 41 \\
\hline Age (years)* & $30(21-49)$ & $42(30-72)$ & $50(29-71)$ & $43(21-72)$ \\
\hline \multicolumn{5}{|l|}{ Gender } \\
\hline Female & $3(100)$ & $6(100)$ & $10(83.3)$ & $19(90)$ \\
\hline \multicolumn{5}{|l|}{ Psychiatry Hx } \\
\hline Yes & $3(100)$ & $5(83.3)$ & $9(75)$ & $17(81)$ \\
\hline No & $0(0)$ & $1(16.7)$ & $3(25)$ & $4(19)$ \\
\hline \multicolumn{5}{|c|}{ Substance abuse } \\
\hline Yes & $2(67)$ & $5(83.3)$ & $8(66.7)$ & $15(71)$ \\
\hline No & $1(33)$ & $1(16.7)$ & $4(33.3)$ & $6(29)$ \\
\hline \multicolumn{5}{|c|}{ Mechanism of injury } \\
\hline IPV & $3(100)$ & $0(0)$ & $5(41.7)$ & $8(38)$ \\
\hline Fall & $0(0)$ & $6(100)$ & $2(16.7)$ & $8(38)$ \\
\hline Incidental & $0(0)$ & $0(0)$ & $5(41.7)$ & $5(24)$ \\
\hline \multicolumn{5}{|c|}{ Location of fractures } \\
\hline $\begin{array}{l}\text { Vertebral } \\
\text { body }\end{array}$ & $5(63)$ & $8(61.5)$ & $20(100)$ & $33(80)$ \\
\hline $\begin{array}{r}\text { Vertebral } \\
\text { process }\end{array}$ & $3(37)$ & $5(38.5)$ & $0(0)$ & $8(20)$ \\
\hline \multicolumn{5}{|c|}{ Type of body fracture } \\
\hline AO type $\mathrm{A}$ & 5 & 8 & 20 & 33 \\
\hline AO type B & 0 & 0 & 0 & 0 \\
\hline AO type $\mathrm{C}$ & 0 & 0 & 0 & 0 \\
\hline $\begin{array}{l}\text { Distribution } \\
\text { in } \\
\text { posterior } \\
\text { element } \\
\text { injuries }\end{array}$ & $\begin{array}{l}\text { Transverse } \\
\text { process } \\
(2,66.7- \\
\%), \\
\text { Lami na } \\
(1,33 \%)\end{array}$ & $\begin{array}{l}\text { Lamina }(1, \\
20.0 \%), \\
\text { transverse } \\
\text { process } \\
(4, \\
80.0 \%),\end{array}$ & $0(0)$ & $\begin{array}{l}\text { Lamina } \\
\qquad(2,25 \%), \\
\text { transverse } \\
\text { process } \\
(6,75 \%\end{array}$ \\
\hline $\begin{array}{l}\text { Concomitant } \\
\text { injuries }\end{array}$ & $\begin{array}{l}\text { Yes }(2, \\
\quad 66.7 \%)\end{array}$ & $\begin{array}{c}\text { Yes }(2, \\
33.3 \%)\end{array}$ & $\begin{array}{l}\text { Yes }(6, \\
50.0 \%)\end{array}$ & $\begin{array}{c}\text { Yes }(10 / 21, \\
47.6 \%)\end{array}$ \\
\hline
\end{tabular}

Unless otherwise specified, data are numbers, with percentages in parentheses

*Data are medians, with ranges in parentheses

$I P V$ intimate partner violence

\section{Results}

Demographics and risk factors Nineteen out of 21 patients $(90 \%)$ were women with a median age of 43 years and a range of 21-72 years. The distribution included Caucasian (15, $71.0 \%)$, African American $(5,24.0 \%)$, and Hispanic (1, $5.0 \%)$ patients. Fifteen out of $21(71 \%)$ had public insurance, and $4 / 21(19 \%)$ patients had private insurance. There was a 
history of psychiatric illness in 17/21 (81\%) and substance abuse in $15 / 21(71 \%)$ patients.

Injury reporting and IPV documentation The reported mechanisms of the spinal injury in the ED were assault by an intimate partner $(8 / 21,38.0 \%)$ and fall $(8 / 21,38.0 \%)$. In $5 / 21$ (24\%) patients, there was no reported history of trauma. IPV screening was documented at the time of injury in $12 / 21$ $(57 \%)$ of the patients. Eighteen out of $21(86 \%)$ patients had IPV documented in their EHR either at the time of current injury or prior to the current injury. Three out of 21 (14\%) had no reported IPV in their chart; however, all 21 patients subsequently reported IPV to the violence prevention program.

Groups These patients were divided into three groups based on the reported mechanism of the injury and age of the vertebral injury (Table 1). Group 1 was comprised of patients with acute injuries on imaging and those who reported assault by an intimate partner at the time of presentation to the $\operatorname{ED}(n=3)$. Group 2 included patients with acute injuries who reported the mechanism of injury as fall to the ED physician $(n=6)$. Group 3 comprised of age indeterminate or chronic injuries on imaging irrespective of the reported history $(n=12)$.

Injury location and pattern A total of 41 spine injuries were identified in 21 patients, involving 38 vertebrae. In total, 33/41 $(80 \%)$ were vertebral body injuries, and 8/41 (20\%) were vertebral process injuries. All injuries were AO type A injuries, with no type $\mathrm{B}$ or type $\mathrm{C}$ injuries. The most common level of the spinal injury was L1 $(8 / 41,19.5 \%)$ followed by L2 $(4 / 41$, $9.8 \%)$ and L4 (4/41, 9.8\%). The next common site was upper and mid-thoracic spine with T2 (2/41, 4.9\%), T3 (3/41, 7.3\%), $\mathrm{T} 4(2 / 41,4.9 \%)$, T5 (3/41, 7.3\%), and T6 (2/41, 4.9\%).

Group 1 consisted of 3 female patients, with a median age of 30 years and a range of 21-49 years. All three of these patients presented to the ED and reported getting assaulted by an intimate partner. A total of 8 vertebral injuries with 5 vertebral body and 3 vertebral process injuries were seen in this group. The first patient underwent MRI of the spine and found to have mild superior end-plate compression deformities of the $\mathrm{C} 7, \mathrm{~T} 2, \mathrm{~T} 3$, and $\mathrm{T} 4$ vertebral bodies with 20-25\% height loss classified as AO type A1 injury (Fig. 1). There was mild edema in the interspinous ligaments but intact ALL, PLL, and ligamentum flavum in keeping with hyperflexion injury. The second patient demonstrated acute fractures of the left transverse processes of the L1 and L2 on CT of the lumbar spine (AO type A0 injury) (Fig. 2). The third patient in this group presented with a gunshot wound (GSW) to the abdomen by her intimate partner. Her CT of the lumbar spine demonstrated AO type A4 burst compression fracture of the L4 with a right laminar fracture.
Group 2 consisted of 6 female patients, with a median age of 42 years and a range of 30-72 years. A total of 13 vertebral injuries were seen in this group of patients with 8 vertebral body and 5 vertebral process fractures. Vertebral process fractures consisted of 4 transverse process and 1 lamina fractures, in keeping with $\mathrm{AO}$ type $\mathrm{A} 0$ or $\mathrm{A} 1$ type of injuries. The most common level of injury in this group was T5 $(3,23.1 \%)$, followed by L1 $(2,15.4 \%)$ and L2 $(2,15.4 \%)$ (Fig. 3). There was one injury each in Coccyx $(1,7.7 \%)$, L4 (1, $7.7 \%)$, Sacrum (1, 7.7\%), T4 (1, 7.7\%), T6 (1, 7.7\%), and $\mathrm{T} 7(1,7.7 \%)$.

Group 3 consisted of 12 patients with 2 males (16.7\%) and 10 females $(83.3 \%)$, with a median age of 50 years and a range of 29-71 years. A total of 20 vertebral injuries were identified in this group with $3 / 20$ chronic (15.0\%) and 17/20 age indeterminate $(85.0 \%)$ injuries. All the injuries were AO type A1 $(20 / 20,100.0 \%)$. There were no vertebral process injuries. The most common level of injury was L1 $(5,25.0 \%)$, followed by T3 $(2,10.0 \%)$ and T12 $(2,10.0 \%)$. There was one injury each in $\mathrm{C} 2(1,5.0 \%), \mathrm{C} 6(1,5.0 \%), \mathrm{L} 2(1,5.0 \%), \mathrm{L} 3(1$, $5.0 \%)$, L4 (1, 5.0\%), Sacrum (1, 5.0\%), T1 (1, 5.0\%), T2 (1, $5.0 \%), \mathrm{T} 6(1,5.0 \%), \mathrm{T} 8(1,5.0 \%)$, and $\mathrm{T} 10(1,5.0 \%)$.

Concomitant injuries Concomitant soft tissue or osseous injuries were identified in 10/21 (48\%) patients; $2 / 3$ in the first group, 2/6 in the second group, and 6/12 in the third group. Of these, craniofacial injuries were the most common, being seen in 5/21 (24\%) patients; 1 from group 1, 1 from group 2, and 3 from group 3. A total of 7 craniofacial injuries were observed on radiological studies in these 5 patients, distributed as 2 soft tissue hematomas, 1 nasal bone fracture, 1 orbital floor fracture, 1 cerebral contusion, 1 subdural hemorrhage, and 1 facial laceration.

The other concomitant injuries were as follows: one of the group 1 patients with GSW had an abdominal injury in the form of small bowel mesentery laceration. One of the group 2 patients had a concomitant grade 2 splenic laceration and sternal fracture. There were 3 patients diagnosed with extremity fractures: 1 femur fracture (group 1), 1 distal tibia fracture (group 2), and 1 distal humerus fracture (group 2).

\section{Discussion}

In summary, we have evaluated 21 patients with IPV with a total of 41 vertebral injuries, involving 38 vertebrae, with the majority being female patients $90 \%$ (19/21) with an average age of 43 years. All vertebral injuries were AO type A injuries with no type $\mathrm{B}$ or $\mathrm{C}$ injuries. The most common level of injury was the upper lumbar spine (L1 and L2) followed by the upper and mid-thoracic spine. None of these patients had any distraction of the spine, spinal canal compromise, or spinal cord injury. History of substance abuse was positive in $71 \%$ victims 
Fig. 1 30-year-old female with reported IPV. Sagittal MRI of the spine with $\mathrm{T} 2 \mathrm{~W}$ (a) and T1W

(b) images show acute compression fracture of the $\mathrm{C} 7, \mathrm{~T} 2, \mathrm{~T} 3$, and $\mathrm{T} 4$ vertebral bodies
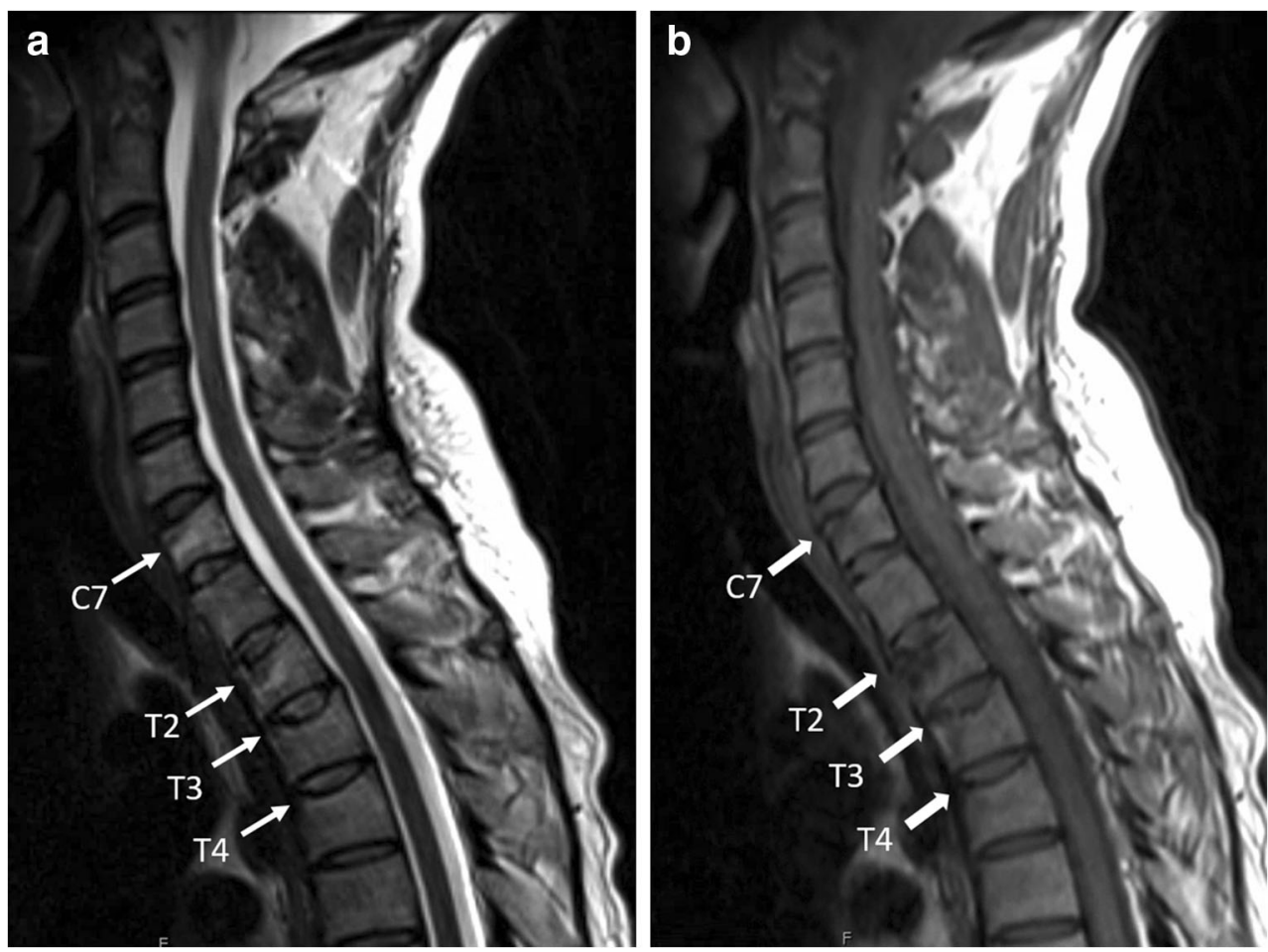

$(15 / 21)$, and psychiatric illness was positive in $80 \%$ victims $(17 / 21)$. Forty-eight percent of the patients (10/21) had concomitant soft tissue or osseous injuries with craniofacial injuries being the most common $(23 \%)$.

IPV was documented in $86 \%$ of the patients in our study group either at the time of the injury or prior to the current episode. Of note, in $14 \%$ of the patients, IPV was not documented in the chart, although these patients subsequently reported IPV at our institution's violence prevention program. This goes on to reiterate the fact that the victims of IPV often

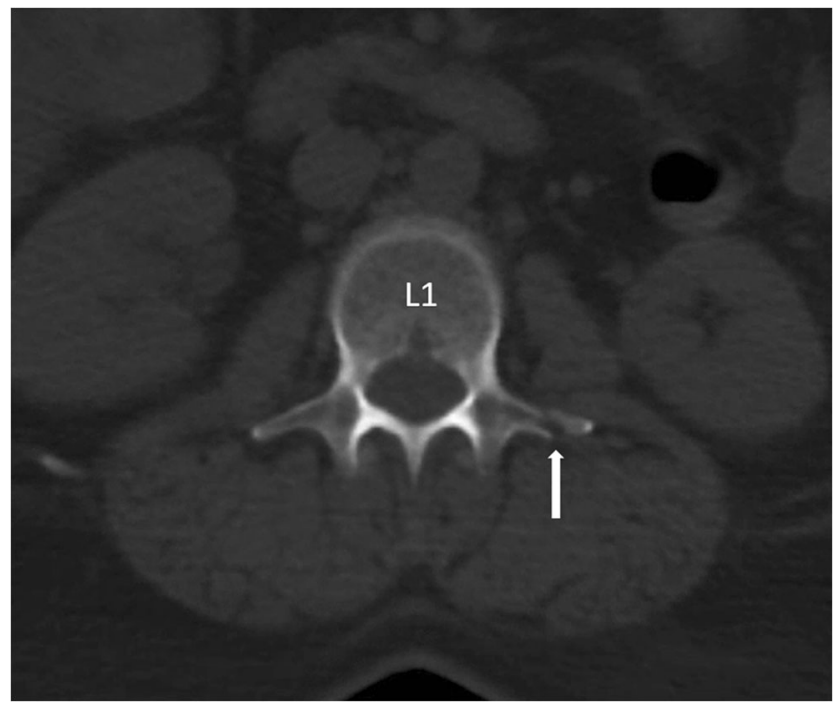

Fig. 2 49-year-old female with reported IPV. Axial CT abdomen images at the level of L1 shows minimally displaced fracture of the left transverse process

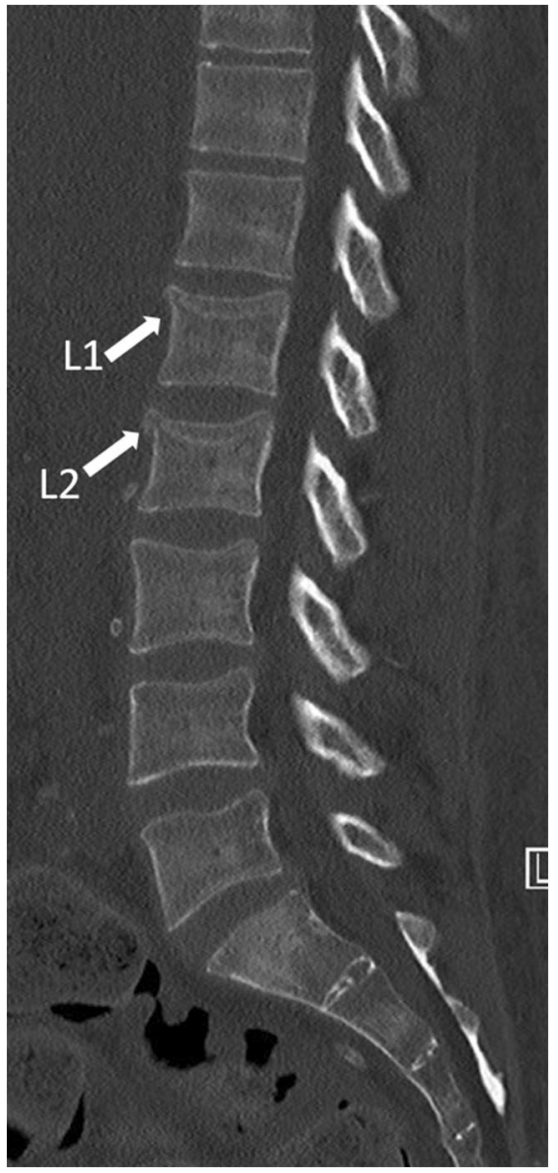

Fig. 3 30-year-old female with reported fall. Sagittal CT of the lumbar spine shows acute mild compression fractures of L1 and L2 with avulsion of the superior-anterior aspects 
conceal their abusive relationship, and many times, physical injures may be inconsistent with the reported mechanism. It is, therefore, essential for the radiologists to be familiar with typical and atypical injury patterns that can be seen on radiological studies with IPV. This has especially become critical with the exacerbation of IPV during the COVID-19 pandemic era and with ED physicians being overwhelmed with treating COVID-19 patients and other healthcare providers following the social distancing measures, thereby missing the opportunities $[10,11]$.

Similar to prior studies, $90 \%$ of IPV victims in our study cohort were women $[1,12,13]$. Approximately 22 to $39 \%$ of women in the USA report some form of physical violence by their partners in their lifetime; however, the proportion of women reporting IPV in the ED or to their healthcare providers still represents the tip of the iceberg $[14,15]$. Wadman et al. found that only $25 \%$ of the victims of domestic violence-related homicides were identified during multiple ED visits at least 2 years prior to the homicide [16]. Even in our cohort of known IPV victims, $14 \%$ of patients did not have any documentation of IPV in their EHR. All these patients subsequently reported IPV to our institution's' domestic violence intervention and prevention program. Still, some of these patients either did not feel comfortable sharing the history or were not provided a safe environment to report IPV to the ED physician or a healthcare provider.

Depression or chronic mental illness has been demonstrated to be an important risk factor for exposure to IPV $[17,18]$. The history of mental illness also increases the risk of subsequent ill health among the victims [18]. Eighty percent of the victims in our study had a history of psychiatric illness auxiliary to the results from the prior studies. Substance abuse has also been linked to the high incidence of IPV [19]. Although it is difficult to assess whether the substance abuse led to the IPV or vice versa, $71 \%$ of our patients had a history of substance abuse documented in their chart.

The incidence of the spinal injuries in our cohort was relatively low (3\%), supporting the common notion that the spine is not a typical target site of abuse. This could also be related to the fact that the most common mechanism of inflicting injury in these victims is blunt force trauma with a fist or with a blunt object $[20,21]$. The most common location of the spinal injury was the vertebral body, with all injuries consistent with AO type A injury, suggesting hyperflexion as the most common underlying mechanism of injury. AO type B and $\mathrm{C}$ injuries which involve posterior tension band or translation and distraction injuries are associated with higher energy mechanisms such as vertical compression or seat belt injury and involve a different vector and intensity of the force [22, 23]. A whiplash-type injury of the spine can occur with nonfatal strangulation because of the violent pulling, pushing, and shaking of the neck by the perpetrator. Our first patient had sustained a classic whiplash, hyperflexion injury of the cervicothoracic junction from being shoved against a wall. Similarly, forceful pulling or lifting with victim resisting and the spine turning away from the perpetrator can result in avulsion fractures of the transverse processes. This was evident in our second patient, who sustained avulsion fractures of the left transverse processes of L1 and L2 likely related to lateral flexion and rotation due to psoas contraction.

The most common level of injury in our patients was the upper lumbar spine (12 out of $38 ; 32 \%$ ), similar to the general population. However, the upper to mid-thoracic spine (11 out of 38) was the second most common region, and only $3 / 38$ fractures were seen in the cervical spine, unlike the general population. Although $\mathrm{C} 2$ is the most common level of fracture in the general population after thoracolumbar junction fractures [24], our cohort had only one patient with C2 fracture. None of our patients had any spinal cord injury. Our study group included one patient with a gunshot wound who had bullet fragments in the lumbar spinal canal. Escalating violence by partners has been observed as the leading cause of homicide in IPV, and penetrating injury like gunshot reflects this later stage of IPV or the most severe form [25].

The most commonly associated injury in our cohort was craniofacial injury $(5 / 21)$. This is not surprising as the head and face are the most commonly injured parts of the body in the victims of IPV [26, 27]. The most common location of the facial injury is the middle third of the face, and in our cohort, there was a nasal bone fracture and an orbital wall fracture.

Our study had several limitations. The retrospective design and a single institution study carry the inherent patient selection bias resulting from the demographics of the population served by the institution. Although we reviewed imaging data of the 688 IPV patients, only 21 patients had spine injuries, limiting the analysis of spinal injuries linked to IPV. Because of significant underreporting of IPV at the time of injury and lack of causal relationship with each injury, we included all injuries besides the IPV as the reported mechanism of injury. However, this could have falsely elevated the number of IPV patients with spine injuries. Finally, it is essential to have a control population to conclude that the injury patterns and locations that we have observed in this study are specific to IPV. However, given high underreporting, it is almost impossible to establish a control group for IPV. We believe our study would create awareness of IPV among radiologists, especially emergency radiologists who often are the first to interpret such studies and can thus save lives by facilitating early detection. To our knowledge, this is the first scientific study describing spine injuries in known victims of IPV. Our results need further validation with prospective case control and multicentre studies.

In conclusion, the incidence of the spinal injuries is relatively low in the victims of IPV with morphological AO type A fracture being the most common type of spinal injury, consisting of mild vertebral body compression and avulsion 
fractures. The upper lumbar spine was the most common level of vertebral injury followed by the upper thoracic spine region, and spinal cord injury was not seen in any of the subjects. A hyperflexion spine trauma without an appropriate history of vehicular deceleration injury could raise the suspicion of IPV. These results will need further validation with prospective case control and larger multicenter studies.

Funding Grant funding from Gillian Reny Stepping Strong for Trauma Innovation, Brigham Health.

\section{Compliance with ethical standards}

Conflict of interest The authors declare that they have no conflict of interest.

Ethical approval Institutional review board approved the above study.

\section{References}

1. Breiding MJ, Smith SG, Basile KC, Walters ML, Chen J, Merrick MT (2014) Prevalence and characteristics of sexual violence, stalking, and intimate partner violence victimization-national intimate partner and sexual violence survey, United States, 2011. MMWR Surveill Summ 63(8):1-18

2. Peterson C, Kearns MC, McIntosh WL, Estefan LF, Nicolaidis C, McCollister KE et al (2018) Lifetime economic burden of intimate partner violence among U.S. adults. Am J Prev Med 55(4):433444. https://doi.org/10.1016/j.amepre.2018.04.049

3. Khurana B, Seltzer SE, Kohane IS, Boland GW (2020) Making the 'invisible' visible: transforming the detection of intimate partner violence. BMJ Qual Saf 29(3):241-244. https://doi.org/10.1136/ bmjqs-2019-009905

4. George E, Phillips CH, Shah N, Lewis-O'Connor A, Rosner B, Stoklosa HM et al (2019) Radiologic findings in intimate partner violence. Radiology. 291(1):62-69. https://doi.org/10.1148/radiol. 2019180801

5. Falschung A (2018) Gender-based violence causing severe multiple injuries; a case report. Adv J Emerg Med 2(3):e35. https://doi.org/ 10.22114/AJEM.v0i0.80

6. Matteoli M, Piacentino D, Kotzalidis GD, Serata D, Rapinesi C, Angeletti G, Rossi M, David V, Dominicis CD (2016) The clinical and radiological examination of acute intimate partner violence injuries: a retrospective analysis of an Italian cohort of women. Violence Vict 31(1):85-102. https://doi.org/10.1891/0886-6708. VV-D-14-00107

7. Vaccaro AR, Oner C, Kepler CK, Dvorak M, Schnake K, Bellabarba C, Reinhold M, Aarabi B, Kandziora F, Chapman J, Shanmuganathan R, Fehlings M, Vialle L, AOSpine Spinal Cord Injury \& Trauma Knowledge Forum (2013) AOSpine thoracolumbar spine injury classification system: fracture description, neurological status, and key modifiers. Spine (Phila Pa 1976) 38(23):2028-2037. https://doi.org/10.1097/BRS. 0b013e3182a8a381

8. Vaccaro AR, Koerner JD, Radcliff KE, Oner FC, Reinhold M, Schnake KJ, Kandziora F, Fehlings MG, Dvorak MF, Aarabi B, Rajasekaran S, Schroeder GD, Kepler CK, Vialle LR (2016) AOSpine subaxial cervical spine injury classification system. Eur Spine J 25(7):2173-2184. https://doi.org/10.1007/s00586-0153831-3
9. Harris PA, Taylor R, Thielke R, Payne J, Gonzalez N, Conde JG (2009) Research electronic data capture (REDCap)-a metadatadriven methodology and workflow process for providing translational research informatics support. J Biomed Inform 42(2):377381. https://doi.org/10.1016/j.jbi.2008.08.010

10. Matoori S, Khurana B, Balcom MC, Koh DM, Froehlich JM, Janssen S et al (2020) Intimate partner violence crisis in the COVID-19 pandemic: how can radiologists make a difference? Eur Radiol. https://doi.org/10.1007/s00330-020-07043-w

11. Gosangi B, Park H, Thomas R, Gujrathi R, Bay CP, Raja AS et al (2020) Exacerbation of physical intimate partner violence during COVID-19 lockdown. Radiology. 202866. https://doi.org/10.1148/ radiol.2020202866

12. O'Doherty L, Hegarty K, Ramsay J, Davidson LL, Feder G, Taft A (2015) Screening women for intimate partner violence in healthcare settings. Cochrane Database Syst Rev 7:CD007007. https://doi.org/ 10.1002/14651858.CD007007.pub3

13. Kimerling R, Iverson KM, Dichter ME, Rodriguez AL, Wong A, Pavao J (2016) Prevalence of intimate partner violence among women veterans who utilize Veterans Health Administration Primary Care. J Gen Intern Med 31(8):888-894. https://doi.org/ 10.1007/s11606-016-3701-7

14. Nelson HD, Bougatsos C, Blazina I (2012) Screening women for intimate partner violence: a systematic review to update the U.S. Preventive Services Task Force recommendation. Ann Intern Med 156(11):796-808, W-279, W-80, W-81, W-82. https://doi.org/10. 7326/0003-4819-156-11-201206050-00447

15. Centers for Disease C, Prevention (2008) Adverse health conditions and health risk behaviors associated with intimate partner violenceUnited States, 2005. MMWR Morb Mortal Wkly Rep 57(5):113117

16. Urrestarazu MI, Liprandi F (1999) Perez de Suarez E, Gonzalez R, Perez-Schael I. [Etiologic, clinical and socio-democratic characteristics of acute diarrhea in Venezuela]. Rev Panam Salud Publica 6(3):149-156. https://doi.org/10.1590/s1020-49891999000800001

17. Lehrer JA, Buka S, Gortmaker S, Shrier LA (2006) Depressive symptomatology as a predictor of exposure to intimate partner violence among US female adolescents and young adults. Arch Pediatr Adolesc Med 160(3):270-276. https://doi.org/10.1001/archpedi. 160.3.270

18. Khalifeh H, Oram S, Trevillion K, Johnson S, Howard LM (2015) Recent intimate partner violence among people with chronic mental illness: findings from a national cross-sectional survey. $\mathrm{Br} \mathrm{J}$ Psychiatry 207(3):207-212. https://doi.org/10.1192/bjp.bp.114. 144899

19. Devries KM, Mak JY, Bacchus LJ, Child JC, Falder G, Petzold M et al (2013) Intimate partner violence and incident depressive symptoms and suicide attempts: a systematic review of longitudinal studies. PLoS Med 10(5):e1001439. https://doi.org/10.1371/journal. pmed.1001439

20. Sheridan DJ, Nash KR (2007) Acute injury patterns of intimate partner violence victims. Trauma Violence Abuse 8(3):281-289. https://doi.org/10.1177/1524838007303504

21. Eskesen TG, Baekgaard JS, Peponis T, Moo Lee J, Saillant N, Kaafarani HMA, Fagenholz PJ, King DR, de Moya M, Velmahos GC, Yeh DD (2019) Cervical spinal cord injury after blunt assault: just a pain in the neck? Am J Surg 217(4):648-652. https://doi.org/ 10.1016/j.amjsurg.2018.06.022

22. Atlas SW, Regenbogen V, Rogers LF, Kim KS (1986) The radiographic characterization of burst fractures of the spine. AJR Am J Roentgenol 147(3):575-582. https://doi.org/10.2214/ajr.147.3.575

23. Anderson PA, Rivara FP, Maier RV, Drake C (1991) The epidemiology of seatbelt-associated injuries. J Trauma 31(1):60-67. https:// doi.org/10.1097/00005373-199101000-00012

24. Wang H, Liu X, Zhao Y, Ou L, Zhou Y, Li C et al (2016) Incidence and pattern of traumatic spinal fractures and associated spinal cord 
injury resulting from motor vehicle collisions in China over 11 years: an observational study. Medicine (Baltimore) 95(43): e5220. https://doi.org/10.1097/MD.0000000000005220

25. Della Rocca GJ, Tornetta P 3rd, Schneider PS, Sprague S (2019) Intimate partner violence and orthopaedics: AOA critical issues. J Bone Joint Surg Am 101(13):e62. https://doi.org/10.2106/JBJS.18. 01341

26. Le BT, Dierks EJ, Ueeck BA, Homer LD, Potter BF (2001) Maxillofacial injuries associated with domestic violence. J Oral
Maxillofac Surg 59(11):1277-1283; discussion 83-4. https://doi. org/10.1053/joms.2001.27490

27. Bhole S, Bhole A, Harmath C (2014) The black and white truth about domestic violence. Emerg Radiol 21(4):407-412. https://doi. org/10.1007/s10140-014-1225-1

Publisher's note Springer Nature remains neutral with regard to jurisdictional claims in published maps and institutional affiliations. 